\title{
The differences between individual project and team project settings in an interdisciplinary REU site
}

\section{Dr. Hua Li, Texas A\&M University, Kingsville}

Dr. Hua Li, an Associate Professor in Mechanical and Industrial Engineering at Texas A\&M UniversityKingsville, is interested in sustainable manufacturing, renewable energy, sustainability assessment, and engineering education. Dr. Li has served as P.I. and Co-P.I. in different projects funded by NSF, DOEd, DHS, and HP, totaling more than 2.5 million dollars.

\section{Prof. Kai Jin, Texas A\&M University - Kingsville}

Dr. Kai Jin is a Professor of Industrial Engineering and Co-PI of the MERIT project. Her research interests include Sustainable Energy, Green Manufacturing, Quality Control, and Multi Objective Decision Making and Optimization as well as Engineering Education. She has served as PI and Co-PI in several DoEd, DHS, NRC, and industry sponsored projects. 


\section{The differences between individual project and team project settings in an interdisciplinary REU site}

\section{Introduction and Project Background}

A Research Experiences for Undergraduates (REU) Site typically involves the principle investigators, faculty advisers, graduate students, and REU participants. Involved personnel plays different roles in the REU site and is closely related to the success of a REU site. In this paper, the authors analyzed and compared the impacts of different elements in an interdisciplinary REU site at Texas A\&M University-Kingsville (TAMUK) on its success in two different settings: individual project and group project. This REU site, titled REU Site: Integrating Research in Sustainable Energy and the Environment across Disciplines (IR-SEED), adopts an interdisciplinary and balanced approach as a guiding principle and provides fundamental research training to REU participants in emerging energy technologies. The IRSEED REU site is multidisciplinary in nature and focuses on different aspects of sustainable energy research, which is designed to provide initial orientation and training on how to conduct research, followed by a period of intensive research experience under the mentorship of a faculty and a graduate student. The detailed IR-SEED REU program design was presented in [1]-[3]. The IR-SEED REU site targets qualified rising junior and senior-level undergraduate students, as well as community college students with special consideration given to underrepresented groups (Hispanics and women). Ten students per year were recruited. In the IR-SEED REU site, the responsibilities of faculty mentors and graduate students included exposing REU participants to energy research, and more importantly, and providing training to REU participants on how to create and arrive at independent research decisions. The principal investigators (PIs) are responsible for coordinating all activities of the IR-SEED REU site, including recruiting and selection, weekly meetings, interactions with faculty mentors, graduate students, and external evaluator, and program evaluation.

In the first year of the IR-SEED REU site, individual project setting was implemented. Each REU participant worked on an individual research project mentored by a faculty adviser and a graduate student. In the second and third years, group project setting was introduced and mixed with individual project setting. In group project setting, two REU participants worked collaboratively under the same project with different individual research activities to achieve the same research objective(s). In the fourth year, all the REU participants worked in group project setting. In addition, each group of REU participants was required to complete a group project report discussing the social impacts of their research projects. In both individual project and group project settings, REU participants were provided ample opportunities to share their research progress through formal and informal presentations in order to enhance REU participants' understanding and broaden their perspective of energy systems challenges. In addition, each REU participant was required to submit an individual final research project report, in order to highlight their findings through an individual poster presentation and give an individual oral presentation at the final IR-SEED REU program ceremony. 


\section{Methods and Results}

In order to collect REU participants' feedback, pre and post surveys were conducted every year together with a follow-up phone interview. Graduate student and faculty advisor surveys were also conducted to compare with students' feedback.

Table 1 shows REU participants' post survey results from the first four years. More than 90\% REU students rated their overall experience as excellent or very good, which matches with the follow-up phone interview results. Although the overall satisfaction/impacts are almost same throughout the four years, REU students indicate significant improvements in different aspects. It should be noted that all the REU participants worked individually in year 1 . In years 2 and 3 , some REU participants worked in group settings. In year 4, all REU participants worked in group settings while each group of REU participants were required to submit an additional team project report discussing the social impacts of their projects.

Table 1: REU participants’ post survey results (data shown in percentage)

\begin{tabular}{|l|c|c|c|c|}
\hline & Year 1 & Year 2 & Year 3 & Year 4 \\
\hline Overall experience (Excellent/Very Good/Good) & $67 / 22 / 11$ & $64 / 27 / 9$ & $55 / 36 / 9$ & $60 / 20 / 10^{*}$ \\
\hline $\begin{array}{l}\text { Interested in going to grad school } \\
\text { (increased/same/decreased) }\end{array}$ & $67 / 33 / 0$ & $73 / 18 / 9$ & $46 / 54 / 0$ & $60 / 40 / 0$ \\
\hline $\begin{array}{l}\text { Interested in research career } \\
\text { (increased/same/decreased) }\end{array}$ & $78 / 22 / 0$ & $64 / 27 / 9$ & $64 / 36 / 0$ & $80 / 0 / 20$ \\
\hline $\begin{array}{l}\text { Highest degree planned to obtain } \\
\text { (increased/same/decreased) }\end{array}$ & $44 / 56 / 0$ & $36 / 55 / 9$ & $36 / 64 / 0$ & $40 / 60 / 0$ \\
\hline
\end{tabular}

( ${ }^{*}$ note: there is one REU participant (10\%) indicated poor as overall experience)

In both pre and post surveys, the REU participants were asked to rate their confidence on 19 different abilities, such as formulating a research question. When comparing the pre and post survey results of 19 different questions, there are some differences among the REU participants' responses throughout the four years. By conducting two-tailed t-test, only one ability (dealing with unanticipated delays in conducting research) shows significant improvement (p-value $<0.05$ ) in year 1, while there are four abilities showing significant improvement in years 2 and 3:

- Formulating a research question

- Planning a research project

- Conducting research

- Making technical presentations

In addition to the four improved abilities in years 2 and 3, REU participants thought their ability of "making formal research presentations" significantly improved in year 4. It is obvious that REU students in years 2, 3, and 4 were more engaged in their research projects than those in year 1. In another follow-up survey sent to 22 REU participants in the first two years, 17 of them thought the IR-SEED REU site should implement collaborative group project setting instead of individual project setting. In the faculty advisor and graduate student surveys' responses, the same observations were noticed. Both faculty advisors and graduate students thought REU participants' general research skills, including technical writing and presentation, were improved more in years 2, 3, and 4 compared to year 1. 
Since year 4 is the first year that all REU participants worked in group project settings, and year 1 is the only year that all REU participants worked in individual project settings, the authors compare the interview results of year 1 with year 4 . The year 4 follow-up phone interviews conducted by an external evaluator shows the following ten significant benefits of the REU project emerged from a crosswalk of themes in REU participants' responses to three of the interview questions:

- The learning achieved.

- Impact on perspective relevant to and plans for the future.

- Encouragement toward involvement with research.

- Confirmation of abilities or areas for further development.

- Confirming interests and intentions related to research, careers, and degrees.

- Providing new experiences and expanding personal horizons.

- Skill development.

- Improving qualifications.

- Increases in confidence.

- Development/expansion of a relational network.

During the interview in year 4, the majority of participants also stated that participation in the program caused them to reflect on or refine their educational goals and career plans. While there are only 6 significant benefits identified by REU participants in year 1, including

- Working with graduate students

- Working with faculty mentors

- Encouragement toward involvement with research

- Field trips

- Independence experienced with their own research projects

- Building relationships with other scholars.

\section{Discussion and Conclusions}

Despite the differences of REU students and research project topics in the four years, It has been concluded that the major reason leading to the improvement in the student engagement is changes in program design. Based on the survey results and interview results, it is clear that group project setting shows advantages of engaging REU participants compared to individual project setting [4].

In the four years of the REU program, there were similar cases every year when faculty advisors or graduate students were not available for more than one week to mentor the REU participants during the 10-weeks summer program due to travel, sickness, or other unexpected emergency. Surprisingly, none of the REU participants in years 1, 2, and 3 complained about the unavailability of faculty advisor or graduate students in the student surveys and phone interviews. However, several REU participants in year 4 complained about this issue.

In post survey results of year 4 REU participants, two REU participants indicated 1) their abilities of working with graduate students were not improved at all due to unavailability of the graduate students, and 2) they needed more time to meet with faculty advisors and graduate students. During the absence of graduate students, the faculty mentors actually met with the two REU 
participants several time a week. In phone interview results of year 4, several recommendations for improving the REU program were presented by the REU participants for the first time in four years:

- Make the advisors consistently available

- Assign a graduate student to each project team.

In addition, several other recommendations were first presented by the REU participants in four years, including:

- Provide students with projects that have relative certainty that the proposed processes will work

- Complete the research summary tasks, presentation and paper, as teams since the students work in teams

- Have each research project ready to begin when the students arrive and provide clearly expressed expectations for each of the research projects regarding processes and desired outcomes.

Although the REU student engagement and benefits received were improved by applying group project setting, it also brought some additional challenges in how the IR-SEED REU program is run. Based on REU participants' feedback in year 4, it can be concluded that coordination and mentorship become more critical on REU participants' expectation and experiences [5]. Since most REU participants did not have previous REU experiences or undergraduate research experience, putting two REU participants working together in the same project requires much better coordination and mentorship from the faculty advisors [6]-[7], graduate students [8]-[9], and PIs. The PIs of the IR-SEED REU site had realized this challenges before year 4 summer program started, and offered additional webinars to all REU participants before they arrived at the IR-SEED REU site. During the webinars, the PIs explained the design of group project settings, and initiated communication between the REU participants in the same team. However, it was unexpected that several REU participants were still confused about their own tasks and responsibilities in the first several weeks in the REU program. In the first three years, the faculty advisors used to provide certain flexibility on the research design so that REU participants may decide the final research objectives and tasks with faculty advisors' approval. It seems like that faculty should provide more clarity and guidance to REU participants when they were finalizing their groups’ research objectives and tasks [7], [10].

With the REU participants' feedback, the authors are still confident that group project setting is better than individual project setting as long as the REU project team pay close attention to the coordination of group research activities and mentorship.

\section{Acknowledgement}

This paper is based upon work supported by the National Science Foundation under Grant No. EEC-1757812. The authors would also like to thank the support from Texas A\&M UniversityKingsville. 


\section{References:}

[1] Li H., \& Abdelrahman, M. (2015). Integrating Research in Sustainable Energy and the Environment Across Disciplines through an NSF-funded REU Site, 122nd ASEE Annual Conference \& Exposition, Seattle, WA, June 14-17.

[2] Li, H., Jin, K., \& Abdelrahman, M. (2017). REU student engagement during and after REU program: a case study comparing individual project with group project, 2017 ASEE Annual Conference \& Exposition.

[3] Li, H., Jin, K., \& Abdelrahman, M. (2018). How to Increase the Impacts of REU Experience in an Interdisciplinary Research Based REU Site, 2018 ASEE Annual Conference \& Exposition.

[4] Alpert, C. L., Levine, E., Barry, C. F., Isaacs, J., Fiorentino, A., Hollar, K., \& Thate, K. (2009). Tackling Science Communication with REU Students: A Formative Evaluation of a Collaborative Approach. In MRS Proceedings (Vol. 1233, pp. 1233-PP04). Cambridge University Press.

[5] Seymour, E., Hunter, A. B., Laursen, S. L., \& DeAntoni, T. (2004). Establishing the benefits of research experiences for undergraduates in the sciences: First findings from a three-year study. Science education, 88(4), 493-534.

[6] Webber, K. L., Laird, T. F. N., \& BrckaLorenz, A. M. (2013). Student and faculty member engagement in undergraduate research. Research in Higher Education, 54(2), 227-249.

[7] Labrador, M. A., \& Pérez, R. (2006). Fulfilling mentors’ expectations: an REU site experience, 2006 Southeast Section Conference of the American Society for Engineering Education.

[8] Hartke, S. G., Isaksen, D. C., \& Wood, P. M. (2006). Graduate Students as Mentors in Mathematics REUs, 2006 Conference on Promoting Undergraduate Research in Mathematics.

[9] Faurot, M. E., Doe, F., Jacobs, E. R., Lederman, N. G., \& Brey, E. M. (2013). From the undergraduate student perspective: The role of graduate students in an undergraduate research program, 2013 ASEE Annual Conference and Exposition.

[10] Jin, K., Li, H., \& Abdelrahman, M. (2015). Minority-focused Engagement Through Research and Innovative Teaching, 2015 ASEE Annual Conference \& Exposition. 